\title{
EARLY OUTCOME OF TOTAL CORRECTION IN ADULT TETRALOGY OF FALLOT PATIENTS.
}

1. MBBS, FCPS (Surgery), FCPS (Cardiac Surgery)

Assistant Professor Paediatric

Cardiac Surgery

Faisalabad Institute of Cardiology Faisalabad.

2. MBBS, FCPS (Paediatric Medicine), FCPS (Paediatric Cardiology) Assistant Professor Paediatric Cardiology

Faisalabad Institute of Cardiology Faisalabad.

3. MBBS, FCPS (Surgery), FCPS (Cardiac Surgery)

Associate Professor Cardiac

Surgery

Rawalpindi Institute of Cardiology,

Rawalpindi.

4. MBBS

Postgraduate Resident MS Cardiac

Surgery

Faisalabad Institute of Cardiology

Faisalabad.

Correspondence Address:

Dr. Zaigham Rasool Khalid

Flat\# 8, FIC Residential Colony,

Faisalabad Institute of Cardiology

Faisalabad.

zaighamdr@yahoo.com

Article received on:

07/01/2020

Accepted for publication:

$12 / 04 / 2020$

\begin{abstract}
Zaigham Rasool Khalid ${ }^{1}$, Abdul Razzaq Mughal ${ }^{2}$, Muhamamd Mujtaba Ali Siddiqui ${ }^{3}$, Riaz ul $\mathrm{Haq}^{4}$
\end{abstract}
ABSTRACT... Objectives: To detect the early outcome of total correction of Tetralogy of Fallot (TOF) in adult patients of age 16 years or above. Study Design: Retrospective descriptive case series. Setting: Paediatric cardiac surgery department of Faisalabad Institute of Cardiology, Faisalabad. Period: October 2016 to June 2019. Material \& Methods: All consecutive patients of age 16 years or above who underwent total correction for TOF during study period were included. Surgical procedure and early outcome measures were recorded and analyzed. Results: Sixty nine patients underwent total correction for TOF during the study period. Majority of patients $(n=55,79.7 \%)$ were between 16 to 25years of age. Male dominated the study population $(56.5 \%, \mathrm{n}=39)$ with male to female ratio 1.3 : 1 . Nine patients $(13 \%)$ had coiling of MAPCA before surgery while prior palliation with Blalock Taussig shunt (BT Shunt) was noted in $5.8 \%$ patients $(n=4)$. All patients were operated with trans-atrial trans-pulmonary approach $(n=69,100 \%)$. Pulmonary artery was augmented with pericardial patch in 22 cases $(32 \%)$ while left pulmonary artery (LPA) augmentation was done in two patients. Pulmonary valve annulus divided in $22 \%$ of patients $(n=15)$, RVOT was reconstructed with trans-annular pericardial patch in $10.1 \%$ patients $(n=7)$ while Pulmonary valve was replaced with tissue valve in 7 patients (10.1\%). In one patient RV to PA continuity was established with contegra. Post operatively inotropic support was given for initial $39 \pm 45$ hours, mean ICU stay was $39 \pm 75$ hours, mean chest drainage $1086 \pm 741 \mathrm{ml}$ and mean requirement for blood transfusion was $2.2 \pm 2.4$ units. As regard early complications, six patients had tiny to small residual VSD (8.7\%) while no patient developed complete heart block. Two patients had neurological complications $(2.9 \%)$, one patient developed renal failure $(1.45 \%)$ while chest reopening was done in two patients due to postoperative bleeding and/ or tamponade $(2.9 \%)$. There was death of two patients $(2.9 \%)$, one had renal failure due to low cardiac output (LCOS) and other had stroke. Conclusion: The early outcome of complete repair of TOF in patients 16 years and above is good with a low mortality and limited number of complications.

Key words: $\quad$ Low Cardiac Output, Pericardial Patch, Stroke, Tetralogy of Fallot, Tamponade.

Article Citation: Khalid ZR, Mughal AR, Siddiqui MMA, Riaz ul Haq. Early outcome of total correction in adult tetralogy of fallot patients. Professional Med J 2020; 27(6):1304-1310. DOI: 10.29309/TPMJ/2020.27.06.4702

\section{INTRODUCTION}

Tetralogy of Fallot (TOF) is one of the most common cyanotic congenital heart defect. ${ }^{1}$ With the advancement in the field of paediatric cardiac surgery there is a tendency to repair the patients of Tetralogy of Fallot at an early age. ${ }^{2}$ In developed countries with early diagnosis and treatment in infant age, the unrepaired TOF is becoming really a rare disease. The natural history of the survivors of unrepaired TOF patients is poor. Twenty five percent of untreated patients die in first year of life, $40 \%$ are dead by the age of 3 and $70 \%$ by 10 years of age..$^{3,4}$ In patients having mild pulmonary stenosis and low right-to-left shunt ratio, right ventricular hypertrophy slowly develops over the years due to pressure overload and these un-operated patients of TOF reach adult life. ${ }^{5}$ In developing countries like Pakistan, the cardiac centres dealing with both adult and paediatric patients for congenital heart surgery, total correction is still among the commonly performed procedures. Repair of adult TOF patients offers certain challenges to surgeon, like polycythaemia with deranged clotting profile, decreased platelet count with dysfunction. ${ }^{6}$ After repair of TOF, patient may develop right ventricular dysfunction, 
bleed more frequently than other patients and requirement of blood and blood products transfusion is higher in adult Tetralogy patients. Post surgically there are some common residual problems such as right ventricular outflow tract obstruction (RVOTO), pulmonary regurgitation and (ventricular) arrhythmia which often require re-interventions. ${ }^{7}$

Most of the data available about belongs to early era of congenital heart surgery. With the better understanding of the disease and its management the outcome of total correction in adult patients has improved significantly even in developing countries like Pakistan. The purpose of this study is to examine whether adults with Tetralogy of Fallot benefit from repair when they are operated at adult age.

\section{MATERIAL \& METHODS}

It was a retrospective descriptive case series conducted in paediatric cardiac surgery department of Faisalabad Institute of Cardiology (FIC) Faisalabad which is a well equipped tertiary cardiac care centre. Seventy four consecutive patients having age 16 years zero day and above who underwent total correction for TOF from October 2016 to June 2019 were enrolled. Approval from ethical committee of the hospital was obtained and there was no conflict of interest. The patients of TOF who underwent an emergent surgery due to endocarditis or had TOF variant anatomy like complete atrioventricular septal defect (CAVSD) with RVOT obstruction and those TOF patients who had prior decreased right ventricle (RV) or left ventricle (LV) function but underwent total correction were excluded from the study. The data of all cardiac surgeries including pediatric heart surgery in our institution is routinely entered in a dedicated database and can be retrieved whenever required. This study was based on retrospective analysis of the data of operated adult TOF patients. Pre-operative demographic profile including age, gender and weight and clinical profile including detailed physical examination, pre-operative transthoracic echocardiography findings and cardiac catheterization detail was retrieved from the data base. Findings of Computed tomography angiography (CT angiography) if performed was also noted. The patients with prior palliative Blalock-Taussig (BT) shunt and patients who underwent coil embolization of significant aortopulmonary collaterals in catheterization laboratory before surgery were also noted.

Procedural parameters including cross clamp time in minutes (min), bypass time (min), lowest temperature attained in degree centigrade $\left(\mathrm{C}^{0}\right)$ were recorded. Per-operative findings like type of VSD (Sub-aortic/Doubly committed/ sub-aortic DORV like), presence or absence of additional VSD, presence or absence of any vegetation, infundibular resection technique (trans-atrial, trans-pulmonary approach/ Infundibulotomy/ ventriculotomy approach), RV infundibulum closure (primarily/ pericardial patchaugmentation/ as part of trans-annular incision) were also noted. RVOT reconstruction technique (transannular pericardial patch/ tissue pulmonary valve replacement/ RV to PA valve conduit) was also noted for each case. Similarly main pulmonary artery (MPA), left pulmonary artery (LPA) or right pulmonary artery (RPA) augmentation was also noted.

Post operative mean ventilation time, inotropic requirements, intensive care unit (ICU) stay (in hours), post operative chest drainage (in millilitre $\mathrm{ml}$ ) and requirement for blood transfusion was recorded from the data base. All patients underwent trans-thoracic Echocardiography in post operative period and noted for any residual VSD, residual obstruction/ gradient at RVOT $(\mathrm{mmHg})$, presence of pulmonary regurgitation (mild/moderate/ free or severe) or tricuspid regurgitation (mild / moderate/ severe). Complications like presence of superficial or deep wound infection, septicaemia, neurological impairment (infarction/ intracranial bleed/fits), and renal failure were also noted. Re-opening of chest (bleeding/tamponade), pneumothorax and death were noted. The required variables were entered in to an investigator designed Proforma and the collected data was analyzed. The mean and the standard deviations were calculated for the quantitative variables like age and weight. The frequencies and percentages were 
calculated for qualitative variables like gender and complications.

\section{Procedure}

All surgeries were done through standard median sternotomy. In case of prior BT shunt, it was dissected prior to establishing cardiopulmonary bypass. Aortic and bicaval cannulation was performed to maintain cardiopulmonary bypass. In patients having severe polycythaemia with haemoglobin $\geq 18 \mathrm{gm} / \mathrm{dl}$, blood removed from cardiopulmonary bypass (CPB) circuit and replaced with crystalloid solution. Haematocrit on the bypass was maintained between $30-35 \%$ in these patients, while in patients with haemoglobin level within normal range, haematocrit was maintained within 24-30\%. In those patients having prior BT shunt, the shunt ligation done immediately after establishing the CPB. The CPB was maintained at the temp of $28-30{ }^{\circ} \mathrm{C}$. Ante grade blood cardioplegia (DelNido) was given through aortic root and repeated after 90 minutes. Venting of the heart was provided via LA vent through inter-atrial septum and Pulmonary artery. VSD closure was done with Dacron patch by interrupted stitches. VSD was approached mostly through Right atrium and rarely through ventriculotomy. Doubly committed VSD (DCSAVSD) approached through combined right atrial and trans-pulmonary approach. In some cases, septal leaflet of tricuspid valve was detached from annulus where exposure of the VSD was not adequate through right atrial approach.

For sub-valvular or right ventricular out tract (RVOT) obstruction excision of hypertrophied muscle bundles in the RVOT was done. In cases of hypo-plastic infundibulum, and cases with DCSA VSD, right ventricle infundibulum was opened below pulmonary valve and augmented with autologous pericardial patch. Main pulmonary artery was opened in all cases, and a sump sucker was placed in distal pulmonary artery. Valvular pulmonary stenosis was addressed with commissurotomy, partial excision or shaving of the thickened leaflets. Our policy in TOF patients is to save pulmonary valve annulus in the patients with Z score -2 to -4 where ever possible. If pulmonary valve annulus is smaller than $Z$ value-4, annulus was divided. Trans-annular incision was kept limited which allows required hegar size snugly through the incision. The RVOT was reconstructed with autologous pericardial patch only, pericardial mono-cusp valve or tissue valve in selected cases accordingly.

Small Pulmonary arteries were augmented with autologous pericardial patch. Thus RVOT was reconstructed by means of either only infundibular patch, only pulmonary artery patch, trans-annular patch or without any patch accordingly. While coming off CPB the haematocrit was targeted more than $30 \%$. After coming off CPB, we used autologous blood for transfusion if it was withdrawn just before bypass, in cases with very high haematocrit. Adrenaline was used as an inotropic support mostly. Milrinone (phosphodiesterase-3 inhibitor) was the second drug used to maintain hemodynamic stability especially in cases where diastolic dysfunction was expected in severely hypertrophied hearts. Nor adrenaline was used in cases where peripheral vascular resistance was low.

\section{RESULTS}

A total of 75 patients underwent total correction for TOF during the study period. Six patients were excluded from the study according to exclusion criteria as two were of CAVSD TOF like anatomy; two had emergent surgery for endocarditis with large vegetations while two patients had severe RV systolic dysfunction. So a total of 69 patients were included in the study according to inclusion criteria.

Male dominated the study population (56.5\%, $\mathrm{n}=39$ ) with male to female ratio 1.3: 1 . Most of the patients were below 25 years of age $(79.7 \%$, $n=55)$. The demographic profile regarding gender, age and weight is shown in Table-l.

All the patients were having cardiac catheterization before surgery. Nine patients (13\%) had coiling of major aorto-pulmonary collateral arteries (MAPCA) before surgery by paediatric cardiologist in the same admission. There were 4 patients of TOF (5.8\%) having prior palliative BT shunt and these underwent BT shunt ligation 
along with total correction. Mean cross clamp time was $95 \pm 36$ minutes and mean bypass time was $122 \pm 43$ minutes while lowest temperature achieved during CPB was $28 \mathrm{C}^{0}$ with a range of 28-30 $\mathrm{C}^{0}$. All patients were operated with transatrial trans-pulmonary approach. VSD was closed with Dacron patch with interrupted $5 / 0$ stitches in all cases. Septal leaflet of tricuspid valve was detached from annulus to improve exposure of VSD in 18 patients (26\%) and reattached after closure of VSD. Important pre surgical and per operative important clinical and operative parameters are shown in Table-I.

\begin{tabular}{|c|c|}
\hline Variables & n (\%) \\
\hline $\begin{array}{l}\text { Demographic Profile } \\
\text { Gender } \\
\text { Male } \\
\text { Female } \\
\text { Age } \\
\text { 16-25 Years } \\
\text { 25-40 Years } \\
\text { 40- } 45 \text { Years } \\
\text { Weight } \\
\text { 30-45 Kg } \\
\text { 45-60 Kg } \\
\text { 60-100Kg } \\
\text { Pre-Surgery } \\
\text { Parameters } \\
\text { Cardiac Catheterization } \\
\text { Coiling of MAPCAs } \\
\text { Prior BT shunt } \\
\text { Operative Findings \& Parameters } \\
\text { VSD } \\
\text { Sub-aortic VSD } \\
\text { Sub-aortic DORV type VSD } \\
\text { Doubly committed sub-aortic VSD } \\
\text { (DCSA VSD) } \\
\text { Additional VSDs } \\
\text { RVOT Resection } \\
\text { Trans-atrial trans-pulmonary approach } \\
\text { Infundibulotomy / Ventriculotomy } \\
\text { Pulmonary valve annulus division } \\
\text { RVOT Reconstruction } \\
\text { Tans-annular patch } \\
\text { Tissue pulmonary valve replacement } \\
\text { RV to PA conduit } \\
\text { Pulmonary artery patch augmentation } \\
\text { LPA patch augmentation } \\
\text { Vegetations }\end{array}$ & $\begin{array}{c}7(10.14 \%) \\
7(10.14 \%) \\
1(1.4 \%) \\
22(32 \%) \\
2(2.9 \%) \\
2(2.9 \%)\end{array}$ \\
\hline
\end{tabular}

All the patients were shifted to ICU from cardiac theatre on inotropic support. The mean ventilation time was $12 \pm 44.8$ hours, inotropic requirement for $39 \pm 45$ hours, mean ICU stay $39 \pm 75$ hours and mean post-operative chest drainage was $1086 \pm 741 \mathrm{ml}$ while mean requirement for blood transfusion was $2.2 \pm 2.4$ units. All the patients were monitored during hospital stay for postoperative bleeding/ tamponade or chest reopening, low cardiac output syndrome (LCOS), renal failure, wound infection, neurological complications, complete heart block and death. Similarly Echocardiography data was retrieved for each operated case to look for hemodynamically significant residual VSD, any RVOT obstruction (mild/moderate/severe or no RVOTO), any TR (trivial/mild/moderate/severe) and for absence or presence of pulmonary regurgitation (trivial/mild/ moderate/severe or free PR). The post-operative parameters of early outcome for morbidity and mortality are shown in Table-II.

\begin{tabular}{|c|c|}
\hline \multirow{2}{*}{\multicolumn{2}{|c|}{$\begin{array}{c}\text { Variables } \\
\text { Post-Operative Morbidity }\end{array}$}} \\
\hline & \\
\hline Echocardiography Findings & \\
\hline & \\
\hline Hemodynamically insignificant (Tiny/Small) & $6(8.7 \%)$ \\
\hline Residual RVOT obstruction/ peak gradient & \\
\hline Mild (between 30-45mmHg) & $8(11.6 \%)$ \\
\hline Moderate (between 45-60mmHg) & 0 \\
\hline Severe (more than $60 \mathrm{mmHg}$ ) & 0 \\
\hline Pulmonary valve regurgitation (PR) & \\
\hline Mild PR & $4(5.8 \%)$ \\
\hline Moderate PR & 0 \\
\hline Free PR & $4(5.8 \%)$ \\
\hline Tricuspid valve regurgitation (TR) & \\
\hline Mild TR & $22(31.9 \%)$ \\
\hline Moderate TR & $3(4.3 \%)$ \\
\hline Electrocardiography & \\
\hline Complete heart block & $0(0 \%)$ \\
\hline Clinical morbidity & \\
\hline Bleeding / Tamponade & $2(2.9 \%)$ \\
\hline Stroke & $2(2.9 \%)$ \\
\hline Renal Failure & $1(1.45 \%)$ \\
\hline Superficial wound infection & $1(1.45 \%)$ \\
\hline Post-operative Mortality & \\
\hline Death & $2(2.9 \%)$ \\
\hline $\begin{array}{l}\text { Renal failure } \\
\text { (due to low cardiac output syndrome) }\end{array}$ & $1(1.45 \%)$ \\
\hline Stroke & $1(1.45 \%)$ \\
\hline
\end{tabular}

Table-II. The post-operative parameters of early outcome for morbidity and mortality 


\section{DISCUSSION}

This study is a single centre analysis of early in hospital outcome of total correction for TOF in sixty nine grown up patients. In earlier era the mortality for repair of TOF was higher which is progressively reduced with the improvement in the operative techniques. In our study the mortality is $3.2 \%$. Operative mortality is age dependent; in experienced centres, it is nearly $0 \%$ for patients 12 months or younger and $4.4 \%$ for patients older than 12 months. Bender and co-workers reported on 84 adult patients, with a hospital mortality of $11.5 \%$ in $1971 .{ }^{8}$ Beech and associates also reported on 64 patients with cyanosis, aged 15 years or older, who had an operative mortality of $1.8 \%{ }^{9}$ which correlates with result in recent literature.

Repair of TOF in our study is via trans-atrial transpulmonary approach which is preferred now-adays. ${ }^{10,11}$ We used trans-atrial trans-pulmonary approach in all patients. In our study $6.4 \%$ patients had prior BT shunt procedure and there was no mortality in this group. Recent literature also states that prior surgical procedures in current era does not impose any mortality risk. ${ }^{12}$

In our study we used trans-annular patch in only $22 \%$ of patients but in literature its use is quite high $30 \%( \pm 5)^{13,14}$, as most of the studies mentioned trans-annular patch include younger patients from infancy to adulthood. The younger the patient, the requirement of trans-annular patch is more. RVOT is reconstructed either with mono-cusp pericardial patch or PTFE patch. ${ }^{15}$ In our study we reconstructed RVOT in cases of trans-annular incision with pericardial patch only, with pulmonary valve replacement (PVR) and with mono-cusp pericardial patch.

Rate of post operative complications in our study is quite low. In earlier data it was quite high but in recent data the complication rate is quite similar to our study. ${ }^{16}$ The amount of bleeding/ drainage is higher $1044 \mathrm{ml}( \pm 746 \mathrm{ml})$ but the rate of reopening is only $3.3 \%$ which is not high and correlated with the data published. Echocardiography is the main diagnostic tool in both pre and post operative period in developing countries. Echocardiography assessment of residual lesions like residual VSD, RVOT obstruction, pulmonary regurgitation, ventricular dysfunction and pericardial effusion is an important step in management of such patients. The data on immediate post operative residual VSD in adult patients repaired for TOF is scanty and most of the available data is from studies on total correction of TOF done in early years of life. In our study only 6 patients (8.7\%) had tiny to small residual hemodynamically insignificant VSD detected on echocardiography during hospital stay. The study is comparable to Tanveer $\mathrm{A}$ et $\mathrm{al}^{17}$ where residual VSD was seen in $8.3 \%$ of patients although the study subjects were between 4 to 18 years of age. Similarly Jalili $Z$ et al study ${ }^{18}$ on total correction in a wide age range of patients showed only two patients had residual VSDs but both were hemodynamically significant and had to undergo redo surgery but in our case residual VSDs were tiny to small and hemodynamically insignificant. Post surgical baseline mild TR or asymptomatic moderate TR has not been associated with progression to severe TR. ${ }^{19}$ Mild TR was seen in $31.9 \%$ while moderate TR in $4.3 \%$ of our subjects and all these subjects were asymptomatic at the time of discharge from the hospital. As regard conduction abnormalities none of our patient had complete heart block which correlates with the Timorian $\mathrm{M}$ et $\mathrm{al}^{20}$ study conducted in Kabul although age range was between 5 to 30 years and total numbers of patients were 180 as compared to our 69 only.

Neurological and renal impairments are well known morbidities in immediate post operative period. In a study conducted in India by Talwar S et $\mathrm{al}^{21}$ showed that there was very low incidence of post operative neurological $(0.3 \%)$ and renal impairment $(0.5 \%)$ in grown up cyanotic congenital heart patients. Our results are comparable to this Indian study although we had a very small number of total subjects and the duration was also very short.

There are few limitations of our study. It is a retrospective study and describes in hospital postoperative outcome only with limited follow up of the patients. 


\section{CONCLUSION}

The number of adult untreated TOF patients is quite high in developing countries. With all over improvement in the specialty of congenital heart surgery the result in this subset of patients is also improved. These patients are usually very symptomatic and have a limited exercise capacity. The outcome of surgery regarding survival after surgery and improvement of the quality of life is quite good.

\section{Copyright(C) 12 Apr, 2020.}

\section{REFERENCE}

1. Bailliard F, Anderson RH. Tetralogy of Fallot. Orphanet J Rare Dis. 2009; 4(1): 2 doi: 10.1186/1750-1172-4-2.

2. Arsdell GV, Maharaj GS, Tom J, Rao VK, Coles JG, Freedom RM, et al. What is the optimal age for repair of Tetralogy of Fallot? Circulation 2000; 102(3): lii 123lii129. doi:10.1161/01.cir.102.suppl_3.iii-123.

3. Kirklin JW, Barratt-Boyes BG. Ventricular septal defect and pulmonary stenosis or atresia. In: Cardiac surgery, $4^{\text {th }}$ ed. New York: Churchill Livingstone, 2012; 1359-1468.

4. Bertranou EG, Blackstone H, Hazelrig JB, Turner $M E$, Kirklin JW. Life expectancy without surgery in tetralogy of Fallot. Am J Cardiol 1978; 42(3):458-66. doi:10.1016/0002-9149(78)90941-4.

5. Erdogan, HB, Bozbuga N, Kayalar N, Erentug V, Omeroglu SN, Kirali K, et al. Long-term outcome after total correction of tetralogy of fallot in adolescent and adult Age. J Card Surg 2005; 20(2): 119123. doi:10.1111/j.0886-0440.2005.200374df.x.

6. Suarez CR, Menendez CE, Griffin AJ, Walenga JM, Fareed J. Canotic congenital heart disease in children: Haemostatic disorders and relevance of molecular markers of hemostasis. semin Thromb Hemost 1984; 10(4): 285-289. doi: 10.1055/s-20071004434.

7. Van der Ven JPG, van den Bosch E, Bogers AJCC and Helbing WA. Current outcomes and treatment of tetralogy of Fallot [version 1; peer review: 2 approved]. F1000Research 2019, 8 (F1000 Faculty Rev):1530 (https://doi. org/10.12688/f1000research.17174.1).

8. Bender HW Jr, Haller JA Jr, Brawley RK, Humphries JO, Neill CA, Gott VL. Experience in repair of tetralogy of Fallot malformations in adults. Ann Thorac Surg 1971; 11 (6): 508-16. doi:10.1016/s0003-4975(10)650655.
9. Beach PM, Bowman FO, Kaiser GA, Malm JR. Total correction of tetralogy of fallot in adolescents and adults. Circulation 1971; 43(37): 12.

10. Karl TR, Sano S, Pornviliwan S, Mee RBB. Tetralogy of Fallot: Favorable outcome of non-neonatal transatrial, transpulmonary repair. Ann Thorac Surg 1992; 54 (5): 903-907. doi: 10.1016/0003-4975(92)90646-I.

11. Dittrich S, Vogel M, Dähnert I, Berger F, Lange PE, Alex-Meskishvili V. Surgical repair of tetralogy of fallot in adults today. Clin Cardiol 1999; 22(7):460-64. doi: $10.1002 /$ clc.4960220705.

12. Seddio F, Migliazza L, Borghi A, Crupi G. Previous palliation in patients with tetralogy of Fallot does not influence the outcome of later repair. $J$ Cardiovasc Med 2007; 8: 119-122. doi: 10.2459/01. JCM.0000260214.27450.c9.

13. Tornell MG, López RA, González RS, Cerdán BA, Ojeda GA, Orozco FC. Treatment of Fallot tetralogy with a transannular patch. Six years followup. Circulation 2015; 83(6): 478-84. doi: $10.1016 /$ j.circen.2015.11.004.

14. Ylitalo $P$, Nieminen $H$, Pitkänen OM, Jokinen E, Sairanen $\mathrm{H}$. Need of transannular patch in tetralogy of Fallot surgery carries high risk of reoperation but has no impact on late survival: Results of fallot repair in Finland. European journal of cardiothoracic surgery 2015; 48(9): 91-97 doi:10.1093/ejcts/ezu401.

15. Fraser FD, McKenzie DE, Cooley DA. Tetralogy of Fallot: Surgical management individualized to the patient. Ann Thorac Surg 2001; 71 (5):1556-63. doi. org/10.1016/S0003-4975(01)02475-4.

16. Khan I, Tufail Z, Afridi S,Iqbal M, Khan T, Waheed A. Surgery for tetralogy of fallot in adults: Early outcomes. Braz J Cardiovasc Surg 2016; 31(4): 300303. doi: 10.5935/1678-9741.20160063.

17. Tanveer R, Khan AU, Siddiqi TA, Siddique S, Nasreen A, Salman-ur-Rehman, et al. Continuous versus interrupted technique of Ventricular Septal Defect (VSD) closure in total correction for Tetralogy of Fallot Pertaining to Residual VSD. J Pak Med Assoc 2010; 60(4): 253-56.

18. Jalili Z, Jalili C, Mahmoodzadeh E. Outcomes of tetralogy of Fallot surgery in Kermanshah, Iran between 1995 and 2010. Acta Medica Mediterranea 2016; 32: 1971-75.

19. Woudstra OI, Bokma JP, Winter $M M$, Kiès $P$, Jongbloed M R M, Vliegen H W, et al. Clinical course of tricuspid regurgitation in repaired tetralogy of Fallot. International Journal of Cardiology 2017; 243:191193. doi:10.1016/j.ijcard.2017.05.122. 
20. Timorian M, Rahman R, Saboor AS. Early outcome after total correction for tetralogy of fallot in department of cardiothoracic and vascular surgery Amiri Medical Complex Kabul Afghanistan. Acta Scientific Paediatrics 2019; 2(7): 08-11. doi: 10.31080/ ASPE.2019.02.0092.
21. Talwar S, Kumar MV, Sreenivas V, Choudhary SK, Sahu $\mathrm{M}$, Airan B. Factors determining outcomes in grown up patients operated for congenital heart diseases. Ann Pediatr Card 2016; 9 (3): 222-8 doi: 10.4103/09742069.189113.

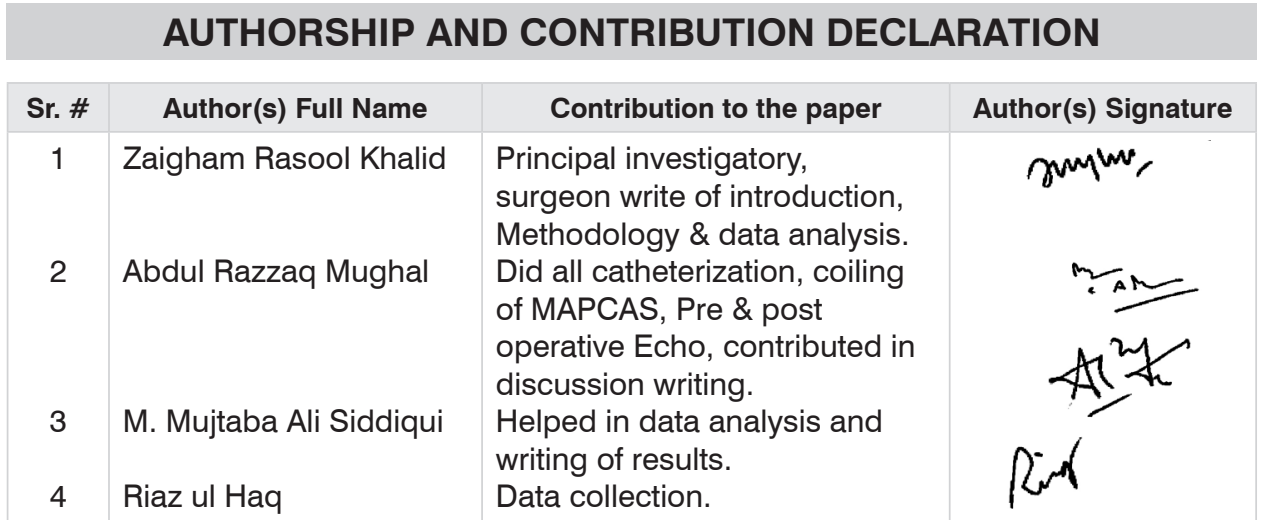

